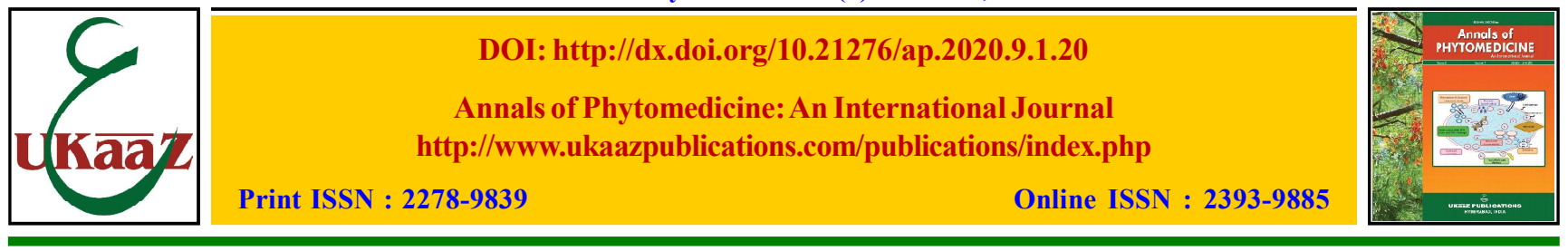

\title{
Extraction kinetics of phenolic compounds from jamun (Syzygium cumini L.) seeds: A statistical approach
}

\author{
Neha Yadav, Ajay Pal*, Shiwani Mandhania, Praduman Yadav*, Bharat Bhushan** and Vinod Saharan*** \\ Department of Biochemistry, CCS Haryana Agricultural University, Hisar-125 004, India \\ *ICAR-Indian Institute of Oilseeds Research, Hyderabad-500 030, India \\ **ICAR-Indian Institute of Maize Research, Ludhiana-141 004, India \\ ***Department of Molecular Biology and Biotechnology, Rajasthan College of Agriculture, Maharana Pratap University of Agriculture and \\ Technology, Udaipur, Rajasthan 313 001, India
}

\section{Article Info \\ Article history \\ Keywords \\ Jamun seeds \\ polyphenolics \\ optimization \\ RSM \\ extraction \\ fatty acid}

Received 15 April 2020

Revised 5 June 2020

Accepted 8 June 2020

Published online 30 June 2020

\begin{abstract}
A process protocol for the extraction of phenolic compounds from jamun seeds was optimized using 'onefactor-at-a-time' followed by response surface methodology (RSM) approach. Initial solvent screening experiments proved $50 \%$ acetone at the ratio of $30: 1$ (solvent:solid, ml:g) suitable for efficient extraction of phenolics. Amount of phenolics marginally increased when the temperature was raised from 30 to $50^{\circ} \mathrm{C}$ followed by a decrease at higher temperatures. The application of RSM showed that volume of solvent and agitation rate exhibited linear and interactive positive effects at $1 \%$ level of significance. Finally, the process was numerically optimized with the constraint of 'minimum' volume of extractant and optimized conditions were: $25 \mathrm{ml} / \mathrm{g}$ volume of solvent (50\% acetone), $193 \mathrm{rpm}$ agitation rate and $150 \mathrm{~min}$ extraction time with the desirability of $\sim 88 \%$. Additionally, four fatty acids namely linoleic $(72.17 \%)$, oleic $(13.88 \%)$, palmitic $(7.91 \%)$ and stearic $(6.03 \%)$ acid were identified and quantified in the final extract. Results of the investigation favor the potential of jamun seed extract as a dietary source of phenolic compounds and $\omega-6$ fatty acid (linoleic acid).
\end{abstract}

\section{Introduction}

Nature has bestowed us with wonderful antioxidant molecules from colored fruits and vegetables which counteract the free radicals and combat oxidative damage in biological entities. These molecules do so by getting themselves oxidized in place of cells. When the availability of antioxidants is limited especially during powerful external stress, free radicals oxidize the biomolecules and membrane system resulting in debilitating oxidative stress (Alberti et al., 2014; Pal et al., 2015).

Shelf-life of fresh as well as processed food depends upon metabolic activity and antioxidants present therein. The shelf-life of fresh food can be increased through cold storage, controlled or modified atmosphere whereas to increase the same of processed food, synthetic antioxidants like butylated hydroxyl toluene (BHT), butylated hydroxyl anisole (BHA) and tert-butyl hydroquinone (TBHQ) are supplemented to it (Dutta et al., 2016). These molecules slow down the oxidative deterioration of food but due to their possible toxic and carcinogenic effects, there has been ever increasing concerns over their use in processing industry (Arabshahi-Delouee

Corresponding author: Dr. Ajay Pal

Assistant Professor, Department of Biochemistry, CCS Haryana Agricultural University, Hisar-125 004, India

E-mail: ajaydrdo@rediffmail.com

Tel.: +91-9466534456; +91-8168668595

Copyright (C) 2020 Ukaaz Publications. All rights reserved.

Email: ukaaz@yahoo.com; Website: www.ukaazpublications.com and Urooj, 2006). As a result, the recommendation of natural antioxidants especially of fruits and vegetable origin has substantially increased by the food scientists. Plants derived antioxidants are safer and endowed with an array of free radical scavenging molecules such as vitamins $\mathrm{C}$, lycopene, tocopherol and other secondary metabolites (Aqil et al., 2012; Pal et al., 2018). Apart from their role in food preservation, secondary metabolites have considerable physiological importance in human system. The search for unexploited sources has focused on the use of colored, wild, medicinal and aromatic plants and/or their parts thereof.

Syzygium cumini L.; commonly known as jamun, black plum and Indian blackberry; is one of the most widely distributed trees in India and belongs to Myrtaceae family. Liver stimulation, digestive, carminative, coolant and hypoglycemic effects of jamun have already been reported. Anti-inflammatory and anti-diarraheal effects of jamun barks and seeds have also been explored (Swamy et al., 2012). Phytochemical analysis of jamun seeds has revealed the presence of alkaloids, flavonoids, glycosides, phytosterols, saponins, tannins and triterpenoids (Kumar et al., 2013). The phenolic compounds especially flavonoids have a role in radical neutralization and maintenance of antioxidant defence system. But, in spite of these phytochemicals, the seeds are not commonly consumed and are considered the waste. In view of the potential of jamun seeds to provide a natural source of antioxidants, our ongoing research is underway to extract, purify and concentrate jamun seed extract, evaluate its antioxidative activity in in vitro and in vivo assays, and improve the stability/shelf-life of polyphenolics. 
To extract the phenolics, solvent extraction is most commonly employed method which depends upon a number of variables like nature of solvent/extractant, time, temperature, solid to liquid ratio, etc. Primitive 'one-factor-at-a-time' approach is time consuming, confusing and misleading where the interactions among various process parameters are ignored and hence the chance of approaching a true optimum is very unlikely. Moreover, to realize the economic feasibility of an industrial process, it requires a process protocol which works with minimum inputs and maximum efficiency. In the extraction processes, where multiple independent variables affect the response/dependent variable, it is desirable to use an optimization method which determines the effects of all factors individually and interactively (Cacace and Mazza, 2003; Pal and Khanum, 2010, 2011). Therefore, the aim of present investigation was to deliver a process protocol using limited number of experiments to efficiently extract the phenolics from jamun seeds.

\section{Materials and Methods}

\subsection{Fruits, chemicals and reagents}

Jamun fruits of similar maturity were procured from the local vendor of Hisar. All the chemicals used in present investigations were of high-quality analytical grade.

\subsection{Sample preparation}

Anatomically distinct parts of jamun fruits such as pulp and seeds were manually separated. Seeds were freed-off from the residual pulp through water wash, wiped-off excess water, chopped and dried at room temperature in dark to avoid any photo-oxidative damage of phenolic compounds. These were then powdered (average particle size $\sim 0.60$ $\mathrm{mm}$ ) and stored in a sealed container in the refrigerator until further use.

\subsection{Optimization strategy}

Various process variables viz. selection of solvent type and its concentration, solvent-to-solid ratio, extraction time, extraction temperature and agitation rate were studied using 'one-factor-at-atime' approach to monitor their effects on the extraction of total phenolic content (TPC) from jamun seeds. Later, interactive effects of three selected variables were studied using central composite rotatable design (CCRD) of RSM.

\subsection{1 'One-factor-at-a-time' approach}

Initially, extraction of TPC in three different solvent systems namely ethanol, methanol and acetone was examined in concentration range $30-100 \%$ in water. Each extraction was carried out at a fixed solventto-solid ratio of $20: 1(\mathrm{ml}: \mathrm{g}), 30^{\circ} \mathrm{C}$ temperature, agitation rate of $120 \mathrm{rpm}$ and 90 min extraction time. The mixture was centrifuged at $10,000 \mathrm{Xg}$ for $10 \mathrm{~min}$ and supernatant/extract was used to quantify TPC. The best solvent type was chosen and further used based on the highest yield of TPC expressed as mg gallic acid equivalent/100 mg powder (mg GAE/100 mg).

Similarly, effect of solvent-to-solid ratio (from 10:1 to 50:1, ml:g), extraction time (from 60 to $180 \mathrm{~min}$ ), extraction temperature (from 30 to $70^{\circ} \mathrm{C}$ ) and agitation rate (from 120 to $210 \mathrm{rpm}$ ) was studied.

\subsubsection{Interactive effect of extraction parameters on the yield of TPC}

A CCRD comprising of 3 variables [volume of solvent ( $\mathrm{ml} / \mathrm{g}$ powder), extraction time ( $\mathrm{min})$ and agitation rate (rpm)] at 5 levels were used to study their interactive effects on the yield of TPC. The experimental domain and matrix along with results are presented in Tables $1 \mathrm{a}$ and $\mathrm{b}$.

Table 1a: The experimental domain

\begin{tabular}{|l|c|c|c|c|c|c|}
\hline Independent & \multirow{2}{*}{ Symbol } & \multicolumn{5}{|c|}{ Range and level } \\
\cline { 3 - 7 } variables & & $-\alpha$ & $-\mathbf{1}$ & $\mathbf{0}$ & $+\mathbf{1}$ & $+\boldsymbol{\alpha}$ \\
\hline Volume of solvent $(\mathrm{ml})$ & $x_{1}$ & 22 & 25 & 30 & 35 & 38 \\
Extraction time $(\mathrm{min})$ & $x_{2}$ & 69.5 & 90 & 120 & 150 & 170.5 \\
Agitation rate (rpm) & $x_{3}$ & 130 & 150 & 180 & 210 & 230 \\
\hline
\end{tabular}

Table 1b: Experimental design and results

\begin{tabular}{|c|c|c|c|c|c|c|}
\hline \multirow[t]{2}{*}{ Run number** } & \multicolumn{3}{|c|}{ Coded level } & \multicolumn{2}{|c|}{ Response (mg GAE/100 mg) } & \multirow[t]{2}{*}{ Relative deviation (\%) } \\
\hline & $x_{1}$ & $x_{2}$ & $x_{3}$ & Observed* & Predicted & \\
\hline 1 & -1 & -1 & -1 & $6.09 \pm 0.05$ & 5.87 & -3.75 \\
\hline 2 & +1 & -1 & -1 & $7.36 \pm 0.09$ & 7.38 & 0.27 \\
\hline 3 & -1 & +1 & -1 & $6.16 \pm 0.12$ & 6.51 & 5.38 \\
\hline 4 & +1 & +1 & -1 & $7.66 \pm 0.15$ & 7.47 & -2.54 \\
\hline 5 & -1 & -1 & +1 & $7.13 \pm 0.23$ & 7.46 & 4.42 \\
\hline 6 & +1 & -1 & +1 & $7.89 \pm 0.06$ & 7.68 & -2.73 \\
\hline 7 & -1 & +1 & +1 & $7.19 \pm 0.21$ & 7.31 & 1.64 \\
\hline 8 & +1 & +1 & +1 & $6.63 \pm 0.18$ & 6.99 & 5.15 \\
\hline 9 & $-\alpha$ & 0 & 0 & $7.47 \pm 0.08$ & 7.19 & -3.89 \\
\hline 10 & $+\alpha$ & 0 & 0 & $8.11 \pm 1.02$ & 8.19 & 0.98 \\
\hline 11 & 0 & $-\alpha$ & 0 & $7.80 \pm 1.07$ & 7.91 & 1.39 \\
\hline 12 & 0 & $+\alpha$ & 0 & $8.18 \pm 0.12$ & 7.87 & -3.93 \\
\hline 13 & 0 & 0 & $-\alpha$ & $5.10 \pm 0.09$ & 5.19 & 1.73 \\
\hline 14 & 0 & 0 & $+\alpha$ & $6.42 \pm 0.13$ & 6.13 & -4.73 \\
\hline 15 & 0 & 0 & 0 & $6.99 \pm 0.32$ & 7.02 & 0.43 \\
\hline 16 & 0 & 0 & 0 & $6.96 \pm 0.05$ & 7.02 & 0.85 \\
\hline 17 & 0 & 0 & 0 & $6.89 \pm 0.09$ & 7.02 & 1.85 \\
\hline 18 & 0 & 0 & 0 & $7.06 \pm 0.06$ & 7.02 & -0.57 \\
\hline 19 & 0 & 0 & 0 & $7.12 \pm 0.09$ & 7.02 & -1.42 \\
\hline 20 & 0 & 0 & 0 & $7.05 \pm 0.12$ & 7.02 & -0.43 \\
\hline
\end{tabular}

*Values are Mean \pm SD of three experiments; ${ }^{* *}$ Serial number of the experiment

Relative deviation $(\%)=\frac{\text { Predicted response }- \text { observed response }}{\text { Predicted response }} \times 100$ 
To develop the regression equation, test factors were coded according to the following equation:

$$
\mathrm{x}_{\mathrm{i}}=\mathrm{X}_{\mathrm{i}}-\mathrm{X}_{0} / \Delta \mathrm{X}_{\mathrm{i}}
$$

where, $\mathrm{x}_{\mathrm{i}}$ is the dimensionless coded value of the $\mathrm{i}^{\text {th }}$ independent variable; $X_{i}$ the natural value of the $i^{\text {th }}$ independent variable; $X_{0}$ the natural value of the $i^{\text {th }}$ independent variable at the center point and $\Delta X_{i}$ the step change value. Once the experiments were performed, the experimental results were fitted with a $2^{\text {nd }}$ order polynomial function:

$\mathrm{Y}=\mathrm{b}_{0}+\mathrm{b}_{1} \mathrm{x}_{1}+\mathrm{b}_{2} \mathrm{x}_{2}+\mathrm{b}_{3} \mathrm{x}_{3}+\mathrm{b}_{11} \mathrm{x}_{1}{ }^{2}+\mathrm{b}_{22} \mathrm{x}_{2}{ }^{2}+\mathrm{b}_{33} \mathrm{x}_{3}{ }^{2}+\mathrm{b}_{12} \mathrm{x}_{1} \mathrm{x}_{2}+\mathrm{b}_{13} \mathrm{x}_{1} \mathrm{x}_{3}$ $+\mathrm{b}_{23} \mathrm{x}_{2} \mathrm{x}_{3}$

where, $\mathrm{Y}$ is the predicted response (yield of TPC); $\mathrm{b}_{0}$ the intercept; $\mathrm{b}_{1}, \mathrm{~b}_{2}, \mathrm{~b}_{3}$ the linear coefficients; $\mathrm{b}_{11} \mathrm{~b}_{22}, \mathrm{~b}_{33}$ the squared coefficients and $b_{12}, b_{13}, b_{23}$ the interaction coefficients.

\subsection{Data analysis}

Design-Expert 7.1.4 (Stat-ease, Inc., Minneapolis, USA) and Minitab 15 (Minitab Inc., State College, PA, USA) softwares were used in statistical designing of experiments and result analysis. Statistical testing of model was carried out by Fisher's statistical test for analysis of variance (ANOVA) to determine the significance of regression model.

\subsection{Estimation of TPC}

TPC was estimated by the method of Folin-Ciocalteu (Kujala et al., 2000). Briefly, $0.5 \mathrm{ml}$ of Folin-Ciocalteu reagent (1N) was added to $3 \mathrm{ml}$ of appropriately diluted extract. The reaction mixture was thoroughly mixed and incubated at room temperature for $10 \mathrm{~min}$. Then, $2 \mathrm{ml}$ of saturated sodium carbonate solution was added and reaction mixture was boiled for $1 \mathrm{~min}$ in a water bath. It was then allowed to cool and absorbance was recorded at $650 \mathrm{~nm}$ using spectrophotometer. Distilled water was used in place of sample extract as reagent blank and rest of the procedure was same. Amount of TPC was calculated using the regression equation of standard curve of gallic acid. The results were expressed as mg gallic acid equivalent per $100 \mathrm{mg}$ powder (mg GAE/100 mg).

\subsection{Fatty acid profiling}

Composition of fatty acids in jamun seed extract (JSE) was analyzed by gas chromatography (GC) (Agilent 7860A) equipped with a flame ionization detector (FID) after derivatization to fatty acid methyl esters. Peak identification was performed by comparing the relative retention times with those of commercial standard mixture of FAME [Supelco 37 Component FAME Mix: palmitic acid (16:0), stearic acid (18:0), oleic acid (18:1) and linoleic acid (18:2)]. Amount of each fatty acid was determined by calculating relative percent peak areas using EZChrom elite compact software (Yadav and Anjani, 2017).

\section{Results}

3.1 Effect of solvent type and its concentration on the yield of TPC

Solvent screening experiments showed that acetone was suitable for efficient extraction of TPC from jamun seed powder at 20:1 ratio, $30^{\circ} \mathrm{C}$ temperature, $90 \mathrm{~min}$ extraction time and $120 \mathrm{rpm}$ agitation rate. The yield of TPC increased with acetone concentration up to $50 \%(6.33 \mathrm{mg} \mathrm{GAE} / 100 \mathrm{mg})$ and then decreased $(1.58 \mathrm{mg} \mathrm{GAE} / 100 \mathrm{mg}$ ) at $100 \%$. Therefore, $50 \%$ acetone was selected as the best extractant for further study (Figure 1a).

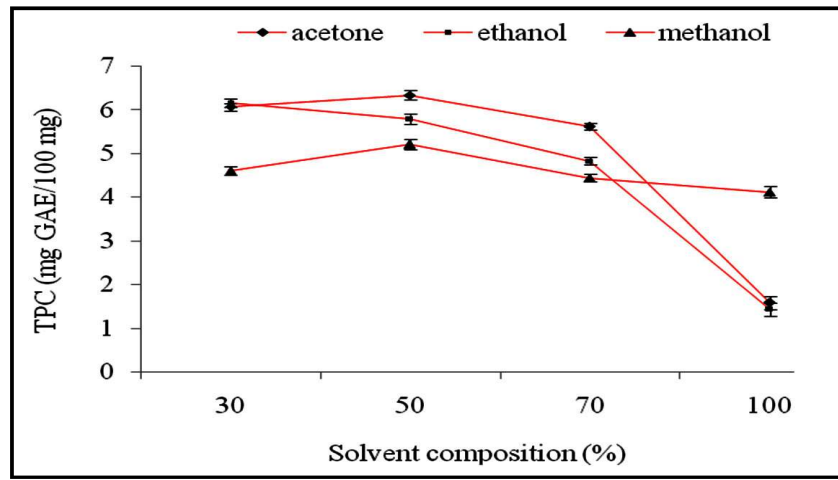

Figure 1a: Effect of solvent type and its concentration on the yield of TPC.

\subsection{Effect of solvent-to-solid ratio on the yield of TPC}

The lowest yield of phenolic compounds from jamun seeds was observed at solvent-to-solid $(\mathrm{ml} / \mathrm{g})$ ratio of 10:1 (5.76 mg GAE/100 $\mathrm{mg})$ while highest yield was found at the ratio of $30: 1(6.43 \mathrm{mg}$ GAE/100 mg) (Figure 1b).

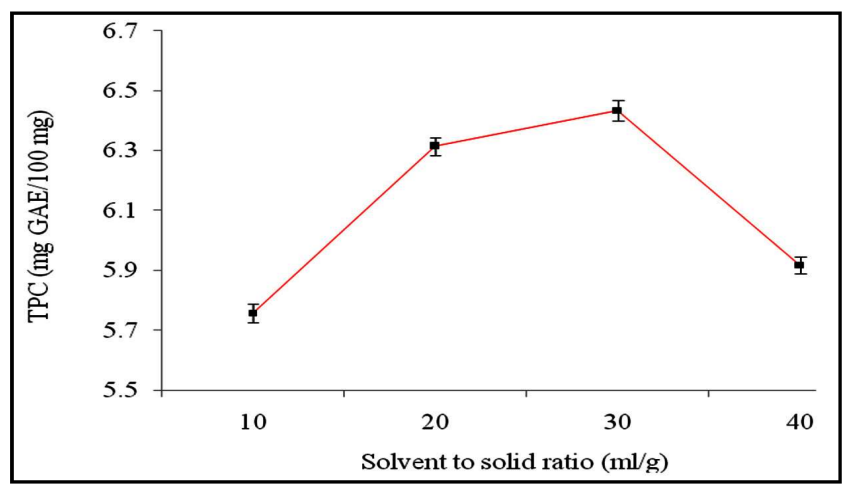

Figure 1b: Effect of solvent-to-solid ratio on the yield of TPC.

\subsection{Effect of extraction time on the yield of TPC}

Effect of extraction time on the yield of phenolics was investigated using $50 \%$ acetone in solvent-to-solid ratio of $30: 1$ at $30^{\circ} \mathrm{C}$ (Figure 1c). Results show that an increase in extraction time from 60 to $120 \mathrm{~min}$ was accompanied with a small increment in TPC from 6.25 to 6.63 $\mathrm{mg} \mathrm{GAE} / 100 \mathrm{mg}$. It was followed by a decrease in yield with further extension of extraction time.

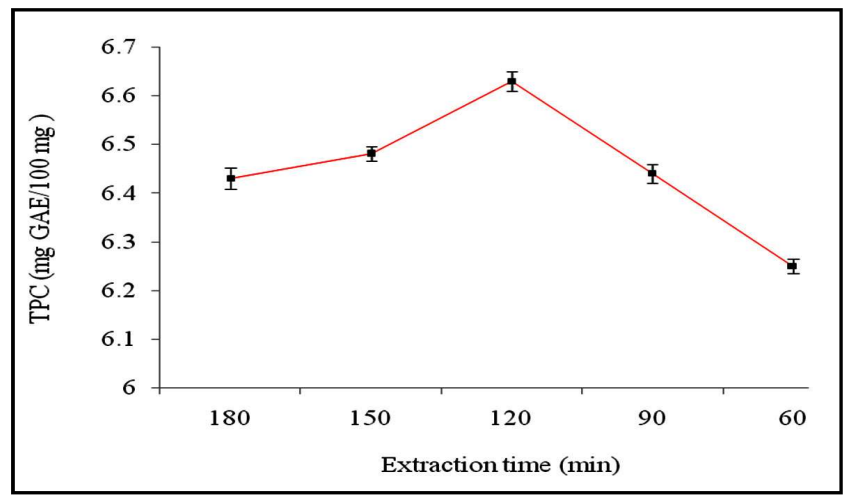

Figure 1c: Effect of extraction time on the yield of TPC. 
3.4 Effect of extraction temperature on the yield of TPC

Amount of phenolics marginally increased when the temperature was raised from $30(6.64 \mathrm{mg} \mathrm{GAE} / 100 \mathrm{mg})$ to $50^{\circ} \mathrm{C}(6.71 \mathrm{mg} \mathrm{GAE} / 100 \mathrm{mg})$, followed by decrease at further higher temperatures (Figure 1d).

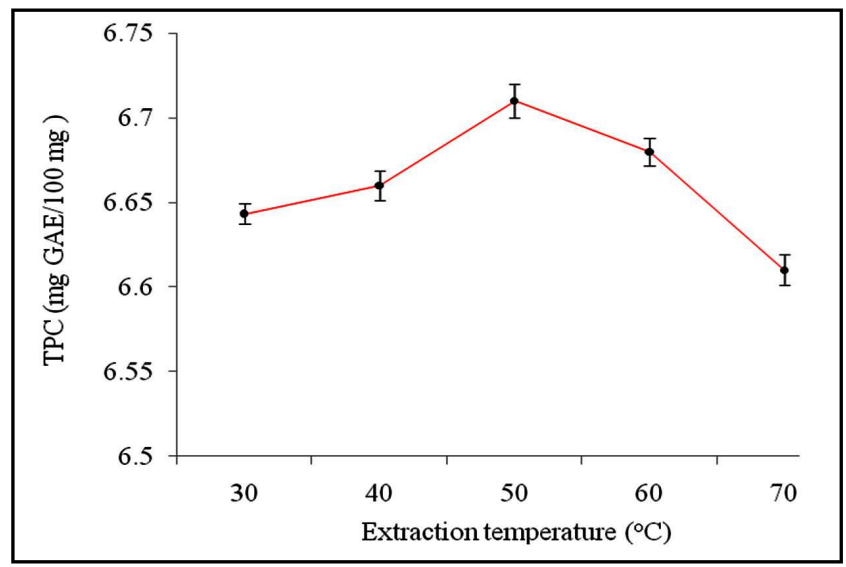

Figure 1d: Effect of extraction temperature on the yield of TPC.

\subsection{Effect of agitation rate on the yield of TPC}

This was the final step in the series of sequential optimization. Here, the yield of phenolic compounds slightly increased when agitation rate was increased from $120(6.70 \mathrm{mg} \mathrm{GAE} / 100 \mathrm{mg})$ to 180 $\mathrm{rpm}(7.06 \mathrm{mg} \mathrm{GAE} / 100 \mathrm{mg})$ followed by decrease at higher agitation rate (Figure 1e).

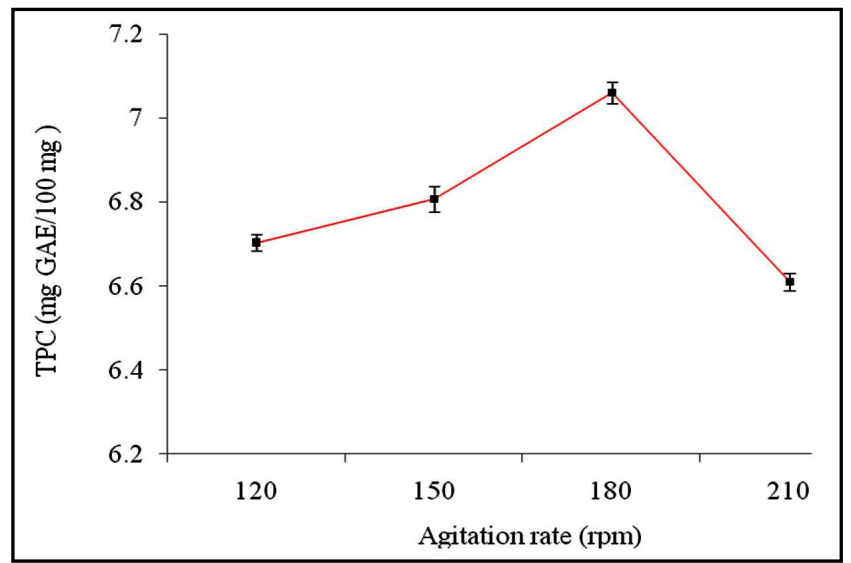

Figure 1e: Effect of agitation rate on the yield of TPC.

\subsection{Interactive effects of extraction parameters on the yield of TPC}

After studying the individual effect of independent variables on the yield of TPC from jamun seed powder, a full factorial CCRD was imposed to study the linear, quadratic and interactive effects of solvent-to-solid ratio ( $\mathrm{ml}: \mathrm{g}$ ), extraction time ( $\mathrm{min}$ ) and agitation rate (rpm). In experimental design, the variable solvent-to-solid ratio was simplified as volume of solvent per gram jamun seed powder $(\mathrm{ml} / \mathrm{g})$.

Based on the results obtained from first set of experiments, $30 \mathrm{ml} / \mathrm{g}$ volume of solvent, 120 min extraction time and $180 \mathrm{rpm}$ agitation rate was selected as the central point of experiment. Solvent type and concentration ( $50 \%$ acetone) as well as extraction temperature $\left(50^{\circ} \mathrm{C}\right)$ were kept constant in all the experiments.
Run number 12 showed the highest yield of TPC ( $8.18 \mathrm{mg} \mathrm{GAE} / 100$ $\mathrm{mg}$ ). Second-order polynomial equation provided clarity of complex experimental data so that experimental values could be fed into multiple regression analysis. In our study, the experimentally obtained values of TPC were very near to the predicted value, indicating a satisfactory model (Table 1b). Based on the model, a regression equation indicating an empirical relation between yield of TPC and test variables could be developed:

Yield of TPC $(\mathrm{mg} \mathrm{GAE} / 100 \mathrm{mg})=7.02+0.30$ volume of solvent 0.014 extraction time +0.28 agitation rate +0.24 volume of solvent $t^{2}$ +0.31 extraction time ${ }^{2}-0.48$ agitation rate ${ }^{2}-0.14$ volume of solvent $\mathrm{X}$ extraction time -0.32 volume of solvent $\mathrm{X}$ agitation rate -0.20 extraction time $\mathrm{X}$ agitation rate.

The volume of solvent exerted a strong positive linear effect on the response $(p<0.003)$. The agitation rate also showed a significant effect whereas effect of extraction time was not significant. Significant interactions were noted between volume of solvent and agitation rate $(p<0.010)$ at $1 \%$ level. Second order terms of volume of solvent, extraction time and agitation rate as well as interaction term of volume of solvent and agitation rate were also equally significant while the remaining terms were insignificant (Table 2a). The computed $F$-value of model was 12.96 as compared with 3.02 of tabulated value while the $\mathrm{R}^{2}$ value was 0.921 (Table $2 \mathrm{~b}$ ). A value of $4.07 \%$ was observed for coefficient of variation. Interactions between two variables while keeping the third at center level are shown in response surfaces and contour graphs (Figures $2 \mathrm{a}$ and $\mathrm{b}$ ). Effect of all three variables on the yield of phenolics is shown in perturbation graph (Figure 3). A comparison of the experimental values with predicted values through polynomial regression model is presented in Figure 4.

Table 2a: Coefficients of regression equation

\begin{tabular}{|l|c|c|c|}
\hline Term & Co-efficient & $\boldsymbol{t}$-value & $\boldsymbol{p}$-value \\
\hline Constant & 7.02 & 59.846 & $<0.0001$ \\
Volume of solvent & 0.30 & 3.808 & 0.003 \\
Extraction time & -0.014 & -0.180 & 0.861 \\
Agitation rate & 0.28 & 3.562 & 0.005 \\
Volume of solvent $^{2}$ & 0.24 & 3.142 & 0.010 \\
Extraction time $^{2}$ & 0.31 & 4.076 & 0.002 \\
Agitation rate $^{2}$ & -0.48 & -6.337 & $<0.0001$ \\
Volume of solvent $^{*}$ Extraction time & -0.14 & -1.340 & 0.210 \\
Volume of solvent & -0.32 & -3.156 & 0.010 \\
* Agitation rate & & & \\
Extraction time & -0.20 & -1.926 & 0.083 \\
* Agitation rate & & & \\
\hline
\end{tabular}

Table 2b: Regression analysis (ANOVA) for yield of TPC

\begin{tabular}{|l|l|l|l|l|l|}
\hline Source & SS & DF & MS & $\boldsymbol{F}$-value & $\boldsymbol{p}$-value \\
\hline Model & 9.6382 & 9 & 1.07091 & 12.96 & 0.0002 \\
Residual & 0.8266 & 10 & 0.08266 & & \\
Total & 10.4648 & 19 & & & \\
\hline
\end{tabular}

SS $=$ Sum of square; DF $=$ Degree of freedom; MS $=$ Mean square $\mathrm{R}^{2}=92.1 \%$; Table $F_{9,10(1 \%)}=3.02 ; \mathrm{C} . \mathrm{V} .=4.07 \%$ 


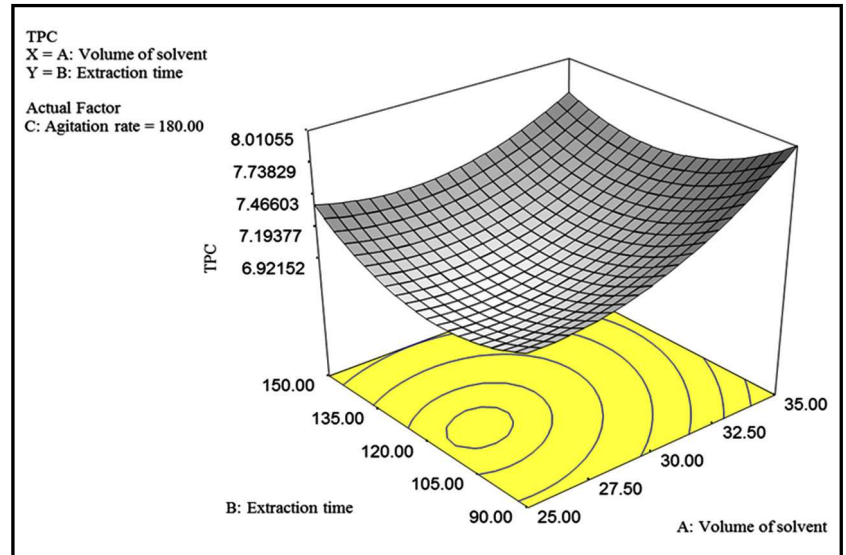

Figure 2a: Effect of volume of solvent and extraction time on the yield of TPC at fixed value of agitation rate.

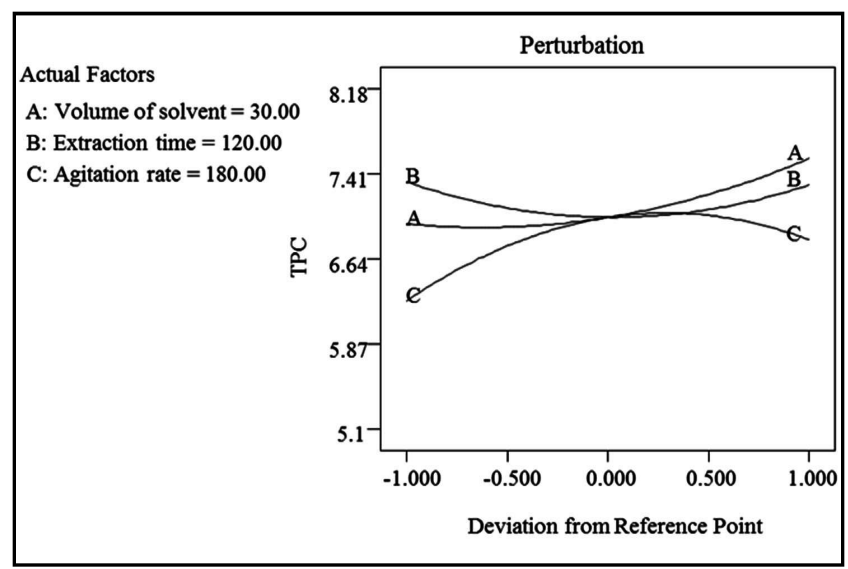

Figure 3: Perturbation graph showing the effect of volume of solvent, extraction time and agitation rate on the yield of TPC.

3.7 Numerical optimization of extraction conditions for the yield of TPC

Design-Expert software was used for numerical optimization of process parameters with the constraint of 'minimum' volume of extractant while keeping extraction time and agitation rate 'in range'

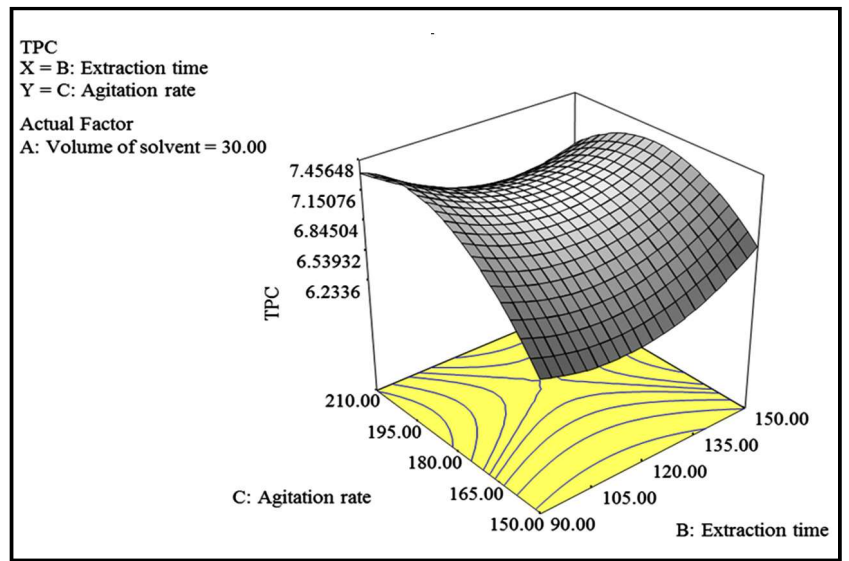

Figure 2b: Effect of extraction time and agitation rate on the yield of TPC at fixed value of volume of solvent.

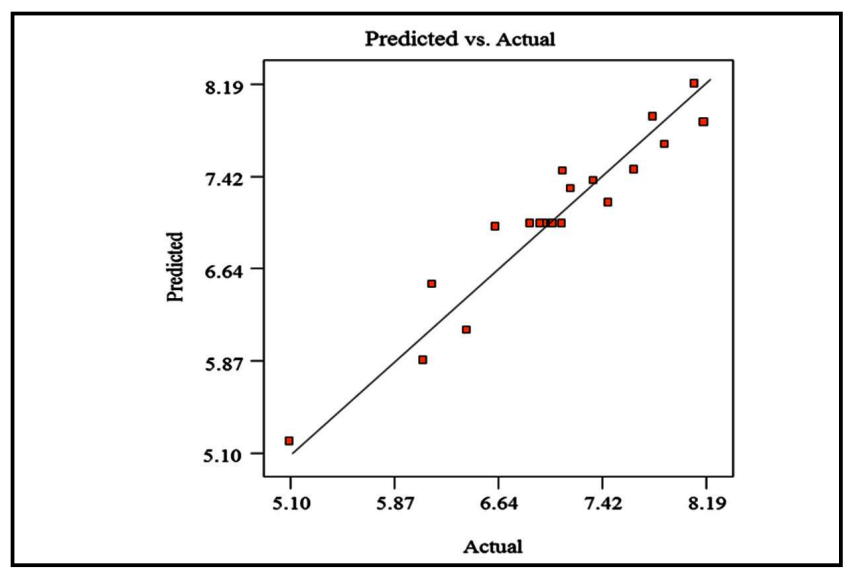

Figure 4: Comparison of the experimental values with the predicted values of yield of TPC.

(Table 3a). The suggested optimal conditions were: volume of solvent $25 \mathrm{ml} / \mathrm{g}$, extraction time $150 \mathrm{~min}$ and agitation rate $193 \mathrm{rpm}$ with a $\mathrm{D}$ function value of 0.878 . Under these conditions, the observed response $(7.30 \pm 0.16 \mathrm{mg} \mathrm{GAE} / 100 \mathrm{mg})$ was $97.72 \%$ to the predicted outcome (7.47 mg GAE/100 mg).

Table 3a: Constraints, criteria for optimization, solution along with predicted and observed response value

\begin{tabular}{|l|l|c|c|c|c|}
\hline Constraints & Goal & Importance & Solution & Observed response* & Desirability \\
\hline Volume of extractant $(\mathrm{ml})$ & Minimize & 3 & 25 & - & - \\
Extraction time (min) & In range & 3 & 150 & - & - \\
Agitation rate (rpm) & In range & 5 & 193 & - & - \\
TPC (mgGAE/100 mg) & Maximize & 5 & 7.47 & $7.30 \pm 0.16$ & 0.878 \\
\hline
\end{tabular}

*Values are Mean \pm SD of three experiments

\subsection{Fatty acid profiling of jamun seed extract}

By employing GC, four fatty acids namely linoleic (72.17\%), oleic (13.88\%), palmitic $(7.91 \%)$ and stearic $(6.03 \%)$ acid were identified and quantified (Table $3 b$ ).
Table 3b: Fatty acids of jamun seed extract

\begin{tabular}{|l|c|}
\hline Fatty acid & Per cent of Total* \\
\hline Palmitic acid $(16: 0)$ & $7.19 \pm 0.02$ \\
Stearic acid $(18: 0)$ & $6.03 \pm 0.02$ \\
Oleic acid $\left(18: 1 \Delta^{9}\right)$ & $13.88 \pm 0.04$ \\
Linoleic acid $\left(18: 2 \Delta^{9,12}\right)$ & $72.17 \pm 0.09$ \\
\hline
\end{tabular}

*Values are Mean $\pm \mathrm{SD}$ of three experiments 


\section{Discussion}

In general, extraction yield and quality depends on multiple process parameters such as temperature, time and polarity of solvent. Their effects may be either independent of each other or interactive (Myers and Montgomery, 2002). Selection of appropriate parameter range is crucial in the extraction of bioactive compounds from plant materials and the conditions can't be generalized due to diverse nature of compounds in different plant materials (Wettasinghe and Shahidi, 1999).

Nature of solvent/extractant plays a pivotal role in solubilising plant matrices. Therefore, selection of appropriate solvent for extraction of phenolic compounds from jamun seed was the prime objective. Various solvents (ethanol, methanol and acetone) were used and their effects on the yield of TPC were examined. The yields of TPC gradually increased with increasing proportion of organic solvents in the extraction media and maximum values were observed when the solvent composition was 50\%. Thereafter, these started to decline regardless of the solvent system (Figure 1a). When solvent composition was $50 \%$, the value of TPC was lowest with methanol and highest with acetone. Ideally, a good solvent system would not only extract the phenolics completely but also at room temperature. Solvent promotes cell lysis and enhances the release of constituents from solid plant matrix (Zhang et al., 2006; Vatai et al., 2009). These findings are similar to the report on extraction of phenolic compounds from dark fig (Bey et al., 2014). An increase of acetone concentration in the solvent causes a decrease in polarity which favors the extraction of less polar components. Nevertheless, at very high acetone concentration, the resulting polarity was inappropriate for the extraction of phenolics. It has also been reported that a single solvent might not be effective for isolation of key bioactive compounds; thus a binary or quaternary system is more effective (Markom et al., 2007). Ilaiyaraja et al. (2015) found that increasing ethanol concentration beyond $70 \%$ dramatically reduced the number of phenolics from wood apple.

Regarding the effect of solvent-to-solid ratio, yield of phenolics increased with increasing ratio up to $30: 1$. It is probably due to the fact that more solvent could enter the cells and more phenolic compounds permeate into solvent under higher solvent-to-solid ratio (Prasad et al., 2009). It may also be due to the increase of driving force for mass transfer of phenolics from powder (Wei et al., 2015). With further increase in solvent-to-solid ratio, a decline in TPC was observed (Figure 1b). Ilaiyaraja and his associates (2015) obtained higher polyphenolic content from wood apple fruits when a solvent:solid ratio of $30: 1(\mathrm{ml}: \mathrm{g})$ was used. A liquid:solid ratio of 40:1 (ml:g) was found sufficient to extract maximum total phenolics from fruits of E. oleraecea (Pompeu et al., 2009). Few researchers, however, have advocated the use of 20:1 ratio to extract maximum phenolics from purple sweet potato and blueberries (He et al., 2016; Zhu et al., 2016). However, from an economic point of view, the requirement of lesser volume is desired as it reduces the overall cost of the process.

Subsequently, the process of extraction was studied at various times using $50 \%$ aqueous acetone at $50^{\circ} \mathrm{C}$. The results showed that yield of TPC increased when extraction time was increased from 60 to $120 \mathrm{~min}$ and then decreased (Figure 1c). This observation can be justified by Fick's second law of diffusion which states that in the processes based on solid-liquid interactions and inter-exchange of molecules between them, a final equilibrium is attained after certain time. So, it is not beneficial to opt a longer time for high yield (Silva et al., 2007). Furthermore, prolonged exposure to temperature, light and/or oxygen might lead to oxidation of phenolics. Our findings are in accordance with the studies of Salar et al. (2016) and Liu et al. (2015) who reported that yield of TPC increased with extraction time and then decreased with further extension of time.

Extraction of phenolic compounds slightly increased when extraction temperature was increased from 30 to $50^{\circ} \mathrm{C}$ as reflected in Figure $1 \mathrm{~d}$. An elevated temperature helps in increasing the yield due to enhanced solubility, faster diffusion rate and increased mass transfer of phenolics. However, a very high temperature promotes the concurrent decomposition of phenolic compounds which have already been released and/or still embedded in the plant matrix. Many reports are available where temperature has drastically affected the yield of TPC from different samples (Bey et al., 2014; Ilaiyaraja et al., 2015). However, Yang et al. (2008) has reported that recovery of phenolic compounds from Gardenia fruits enhanced linearly with increase in temperature and extraction time.

Agitation rate is another key factor influencing the yield of TPC. Its effect was investigated in the range 120-210 rpm where yield of phenolic compounds slightly increased when agitation rate was up to $180 \mathrm{rpm}$. It was followed by a decrease at higher agitation rate as reflected in Figure 1e. This may be because of the fact that increasing agitation rate up to $180 \mathrm{rpm}$ resulted in effectual collision among molecules while higher agitation rates resulted in more vigorous mixing which spun around the mixture, decreased the effective contacts and ultimately resulted in reduced yield. Our current findings are in concurrence with the report of Sushma et al. (2014) on the extraction of polyphenols from the roots of Decalepis hamiltonii.

In the second phase of optimization, CCRD was applied to study the interactive effects of volume of solvent $(\mathrm{ml} / \mathrm{g})$, extraction time (min) and agitation rate (rpm) on the yield of TPC and to derive a statistical model for their effects. Regression coefficients were used to study the impacts of variables on extraction yield and their significance was determined by Student's $t$-value and $p$-value (Table 2a). Smaller the $p$ - and larger the $t$-value, the more significant is the corresponding co-efficient (Myers and Montogomery, 2002). Sign and magnitude of co-efficient indicate the effect of variable on the response. Negative sign of coefficient at linear level indicates decrease in response with an increase in level of variable. The computed $F$-value (12.96) was almost 4 -fold higher than tabulated value $\left(F_{9,10(1 \%)}=3.02\right)$. Fisher $F$-test with a very low probability value $(0.0002)$ demonstrates a very high significance of regression model and confirms the adequacy of quadratic model. Regression equation indicated $R^{2}$ value of 0.921 (a value of $R^{2}>0.75$ indicates the aptness of model) (Table $2 \mathrm{~b}$ ). This value ensures a satisfactory adjustment of quadratic model to explain the experimental data and indicates that model could explain $\sim 92 \%$ of the variability in response and only less than $8 \%$ of the total variation could not be explained by the model. A high value of $\mathrm{R}^{2}$ illustrates that the selected statistical model is well adapted to achieve the response (Liyana-Pathirana and Shahidi, 2005). Coefficient of variation (CV) is a measurement for percent relative standard deviation (\% RSD). Its lower value $(4.07 \%)$ shows that the experiments conducted were precise and reliable. Usually, $<5 \%$ value shows that results 
are reproducible while a high $\mathrm{CV}$ makes the selected model unacceptable. To add, small value gives better reproducibility while high value indicates non-reproducibility of the model (Daniel, 1991).

The relationships between independent and dependent variables are illustrated in 3D representations of response surfaces and 2D contour plots. Each contour curve represents an infinite number of combinations of two test variables with the other one maintained at its center level (Figures $2 a$ and $b$ ). The effects of variations in level of all three independent variables on the yield of TPC are shown in perturbation graph (Figure 3). Plot reveals that yield of TPC was sensitive to changes in all the variables. The yield increased with increase in agitation rate up to center value and then decreased. The volume of solvent increased the yield of phenolics while extraction time had no discernable effect. Comparison of the experimental values with the predicted values of yield demonstrates that the polynomial regression model was in good agreement with the experimental results (Figure 4). In this figure, each of the observed values is compared to the predicted value calculated from the model. The results suggest that model used in this investigation was able to identify best operating conditions for maximum extraction of TPC from jamun seeds.

Optimization is essential for each process since it directly affects the quality of product and economy of process. Design-Expert software was used for numerical optimization of process parameters. Our main aim was to 'minimize' the volume of extractant while keeping extraction time and agitation rate 'in range' (Table 3a). RSM approach and response desirability function (D) provide simultaneous optimization of a response. Application of D provided optimal conditions for response variable as: $25 \mathrm{ml} / \mathrm{g}$ volume of solvent, $150 \mathrm{~min}$ extraction time and $193 \mathrm{rpm}$ agitation rate; while D function was still substantially high (0.878). Balyan and Sarkar (2017) have optimized the extraction protocol with the following conditions: $49.2^{\circ} \mathrm{C}, 89.4 \mathrm{~min}$, and $51.6: 1 \mathrm{ml}$ solvent/g biomass with an yield of $415 \mathrm{mg} \mathrm{GAE} / \mathrm{g}$. High temperature $\left(54^{\circ} \mathrm{C}\right)$, less time (50 $\mathrm{min}$ ), and the economical liquid-to-solid ratio of $8.5: 1$ for substantial TPC yield (1.33 g GAE/100 g) has been observed by Maran et al. (2014). Under selected criterion of process parameters, response desirability of $87.8 \%$ was targeted and the observed response $(7.30 \pm 0.16 \mathrm{mg} \mathrm{GAE} / 100 \mathrm{mg})$ was $97.72 \%$ of the predicted outcome (7.47 mg GAE/100 mg).

Finally, an attempt was made to identify the main fatty acids present in jamun seed extract. By employing GC, four fatty acids namely linoleic (72.17\%), oleic (13.88\%), palmitic (7.91\%) and stearic $(6.03 \%)$ acid were identified and quantified (Table $3 \mathrm{~b}$ ). It is evident that extract possesses substantial amount of $\omega-6$ fatty acid (linoleic acid) which is known to maintain the integrity and functionality of cellular membranes. It is also clearly established that dietary intake of $\omega-3 / 6$ prevents physiological disorders such as coronary heart diseases and atherosclerosis through lowering the LDL content (Ramsden et al., 2013). All these observations support the use of jamun seed extract as a source of phenolic compounds and $\omega-6$ fatty acid.

\section{Conclusion}

In the present study, CCRD of RSM was successfully used for the extraction of phenolic compounds from jamun seeds. The independent variables (agitation rate, extraction time, and volume of extractant) had a great impact on the yield of phenolic compounds. With the desired constraint of 'minimum' volume of extractant, the optimized conditions were: $193 \mathrm{rpm}$ agitation rate, 150 min extraction time and 25:1 ratio of solvent to solid. Minimum usage of solvent can make the extraction process cost-effective. The present piece of research work provides a platform for industrial exploitation of jamun seeds as a source of phenolic compounds and essential fatty acid.

\section{Acknowledgments}

Authors thank head of the Department of Biochemistry for providing necessary facilities to execute the present research work.

\section{Conflict of interest}

The authors declare that there are no conflicts of interest in the course of conducting the research. All the authors had final decision regarding the manuscript and decision to submit the findings for publication.

\section{References}

Aqil, F.; Gupta, A.; Munagala, R.; Jeyabalan, J.; Kausar, H.; Sharma, R.C.; Singh, I.P. and Gupta, R.C. (2012). Antioxidant and antiproliferative activities of anthocyanin/ellagitanin enriched extracts from Syzygium cumini L. Nutr. Cancer, 64:428-438.

Alberti, A.; Zielinski, A.A.F.; Zardo, D.M.; Demiate, I.M.; Nogueira, A. and Mafra, L.I. (2014). Optimisation of the extraction of phenolic compounds from apples using response surface methodology. Food Chem., 149: $151-158$.

Arabshahi-Delouee, S. and Urooj, A. (2006). Antioxidants properties of various solvent extracts of mulberry. Food Chem., 102:1233-1240.

Balyan, U. and Sarkar, B. (2017). Aqueous extraction kinetics of phenolic compounds from Jamun (Syzygium cumini L.) seeds. Int. J. Food Prop., 20:372-389.

Bey, M.B.; Meziant, L.; Benchikh, Y. and Louaileche, H. (2014). Deployment of response surface methodology to optimize recovery of dark fresh fig (Ficus carica L., var. Azenjar) total phenolic compounds and antioxidant activity. Food Chem., 162:277-281.

Cacace, J.E. and Mazza, G. (2003). Optimization of extraction of anthocyanins from black currants with aqueous ethanol. J. Food Sci., 68:240-248.

Daniel, W. W. (1991). Biostatistics: A foundation for analysis in the health sciences. John Wiley, New York, pp:265-316.

Dutta, S.; Roy, D.; De, A.; Dutta, C. and Bhattacharya, S. (2016). Antioxidant and free radical scavenging activity of Trigonella foenum-graecum L, Murraya koenigii, Coriandrum sativum and Centella asiatica. Turk. J. Agric. Food Sci. Technol., 4:255-261.

He, B.; Zhang, L.; Yue, X.Y.; Liang, J.; Jiang, J.; Gao, X.L. and Yue, P.X. (2016). Optimization of ultrasound-assisted extraction of phenolic compounds and anthocyanins from blueberry (Vaccinium ashei) wine pomace. Food Chem., 204:70-76.

Ilaiyaraja, N.; Likhith, K.R.; Babu, G.R.S. and Khanum, F. (2015). Optimization of extraction of bioactive compounds from Feronia limonia (wood apple) fruit using response surface methodology (RSM). Food Chem., 173:348-354.

Kujala, T.S.; Loponen, J.M.; Klika, K.D. and Pihlaja, K. (2000). Phenolic and betacyanins in red beetroot (Beta vulgaris) root: distribution and effects of cold storage on the content of total phenolics and three individual compounds. J. Agric. Food Chem., 48:5338-5342.

Kumar, S.; Mishra, A. and Pandey, A.K. (2013). Antioxidant mediated protective effect of Parthenium hysterophorus against oxidative damage using in vitro models. BMC Compl. Alt. Med., 13:120. 
Liu, X.; Jiang, F.; Gao, P.; Jin, M.; Yang, D.; Nian, Z.F. and Zhang, Z. (2015). Optimization of extraction conditions for flavonoids of Physalis alkekengi var. franchetii stems by response surface methodology and inhibition of acetyl cholinesterase activity. J. Mex. Chem. Soc., 59:59-66.

Liyana-Pathirana, C. and Shahidi F. (2005). Optimization of extraction of phenolic compounds from wheat using response surface methodology. Food Chem., 93:47-56.

Maran, J.P.; Sivakumar, V.; Thirugnanasambandham, K. and Sridhar, R. (2014) Extraction, multi-response analysis, and optimization of biologically active phenolic compounds from the pulp of Indian Jamun fruit. Food Sci. Biotechnol., 23:9-14.

Markom, M.; Hasan, M.; Ramli, W.; Daud, W.; Singh, S. and Jahim, J.M. (2007) Extraction of hydrolysable tannins from Phyllanthus niruri Linn.: Effects of solvents and extraction methods. Separ. Purif. Technol., 52:487-496.

Myers, R.H. and Montgomery, D.C. (2002). Response surface methodology: Process and product optimization using designed experiments, Wiley, New York, pp:824.

Pompeu, D.R.; Silva, E.M. and Rogez, H. (2009). Optimization of the solvent extraction of phenolic antioxidants from fruits of Euterpe oleracea using response surface methodology. Biores. Technol., 100:6076-6082.

Pal, A. and Khanum, F. (2010). Production and extraction optimization of xylanase from Aspergillus niger DFR-5 through solid-state-fermentation. Biores. Technol., 101(19):7563-7569.

Pal, A. and Khanum, F. (2011). Identification and optimization of critical medium components using statistical experimental designs for enhanced production of xylanase from Aspergillus flavus DFR-6. Food Technol. Biotechnol., 49(2):228-236.

Pal, A.; Kumar, M.; Saharan, V. and Bhushan, B. (2015). Antioxidant and free radical scavenging activity of Ashwagandha (Withania somnifera L.) leaves. J. Global Biosci., 4(1):1127-1137.

Pal, A.; Bhushan, B.; Saharan, V. and Narwal, R.K. (2018). Extraction and evaluation of antioxidant and free radical scavenging potential correlated with biochemical components of red rose petals. Iran. J. Sci. Technol. Trans. A: Sci., 42(3):1027-1036.

Prasad, N.K.; Chun, Y. En, Y.; Zhao, M. and Jiang, Y. (2009). Effects of high pressure on the extraction yield, total phenolic content and antioxidant activity of Longan fruit pericarp. Innov. Food Sci. Emerg. Technol., 10:155-159.
Ramsden, C.M.; Zamora, D.; Leelarthaepin, B.; Sharon, F.M.; Faurot, K.R.; Suchindran, C.M. and Hibbeln, J.R. (2013). Use of dietary linoleic acid for secondary prevention of coronary heart disease and death: Evaluation of recovered data from the Sydney diet heart study and updated meta-analysis. British Med. J., 346:1-18.

Salar, R.K.; Purewal, S.S. and Bhatti, M.S. (2016). Optimization of extraction conditions and enhancement of phenolic content and antioxidant activity of pearl millet fermented with Aspergillus awamori MTCC-548. Resource-Efficient Technol., 3:148-157.

Silva, E.M.; Rogez, H. and Larondelle, Y. (2007). Optimization of extraction of phenolics from Inga edulis leaves using response surface methodology. Separ. Purif. Technol., 55:381-387.

Sushma, R.; Dharini, H.; Tabassum, S.; Murthy, K.T.P.; Bhavya, S.G. and Dammalli, M. (2014). Extraction of polyphenols from Decalepis hamiltonii root: Optimization of batch extraction process parameters. Res. J. Pharma. Biol. Chem. Sci., 5:625-632.

Swami, S.B.; Thakor, N.S.J.; Patil, M.M. and Haldankar, P.M. (2012). Jamun [Syzygium cumini (L.)]: A review of its food and medicinal uses. Food Nutri. Sci., 3:1100-1117.

Vatai, T.; Skerget, M. and Knez, Z. (2009). Extraction of phenolic compounds from elder berry and different grape marc varieties using organic solvents and/or supercritical carbon dioxide. J. Food Engineer., 90:246-254.

Wei, L.; Zhang, W.; Yin, L.; Yan, F.; Xu, Y. and Chen, F. (2015). Extraction optimization of total triterpenoids from Jatropha curcas leaves using response surface methodology and evaluations of their antimicrobial and antioxidant capacities. Electronic J. Biotechnol., 18:88-95.

Wettasinghe, M. and Shahidi, F. (1999). Evening primrose meal: A source of natural antioxidants and scavenger of hydrogen peroxide and oxygen-derived free radicals. J. Agric. Food Chem., 47:1801-1812.

Yadav, P. and Anjani, K. (2017). Assessment of variation in castor genetic resources for oil characteristics. J. Amer. Oil Chem. Soc., 94(4): 611-617.

Yang, B.; Zho, M. and Jiang, Y. (2008). Optimisation of tyrosine inhibition activity of ultrasonic extracted polysaccharides from longan fruit pericarp. Food Chem., 110:294-300.

Zhang, S.; Chen, R.; Wu, H. and Wang, C. (2006). Ginsenoside extraction from Panax quinquefolium L. (American ginseng) root by using ultrahigh pressure. J. Pharma. Biomed. Anal., 41:57-63.

Zhu, Z.; Guan, Q.; Guo, Y.; He, J.; Liu, G.; Li, S.; Barba, F.J. and Jaffrin, M.Y. (2016). Green ultrasound-assisted extraction of anthocyanin and phenolic compounds from purple sweet potato using response surface methodology. Inter. Agrophy., 30:113-122.

Citation: Neha Yadav, Ajay Pal, Shiwani Mandhania, Praduman Yadav, Bharat Bhushan and Vinod Saharan (2020). Extraction kinetics of phenolic compounds from jamun (Syzygium cumini L.) seeds: A statistical approach. Ann. Phytomed., 9(1):154-161. http://dx.doi.org/10.21276/ap.2020.9.1.20 